\title{
Sosialisasi Sumur Resapan sebagai Upaya Penanggulangan Banjir di Wilayah Singonegaran, Kota Kediri
}

\author{
Sony Susanto ${ }^{1^{*}}$, Sigit Winarno ${ }^{1}$, Yosef Cahyo Setianto ${ }^{1}$, Eko Siswanto ${ }^{1}$ \\ 1Prodi Teknik Sipil Universitas Kadiri, Kediri, Jl. Selomangkleng No 1, Kediri, 64115 \\ *Email koresponden: sonysusanto@unik-kediri.ac.id
}

\author{
ARTICLE INFO \\ Article history \\ Received: 27 Jan 2021 \\ Accepted: 25 Mar 2021 \\ Published: 15 Apr 2021
}

\section{Kata kunci: \\ Banjir \\ Penanggulangan \\ Sumur Resapan}

\section{Keyword: \\ Countermeasures \\ Floods \\ Infiltration wells}

\begin{abstract}
A B S T R A K
Background: Sumur resapan ini merupakan cara yang cukup praktis dan ramah lingkungan yang berfungsi untuk mempercepat penyerapan air hujan banjir. Tujuan dari pengabdian masyarakat ini adalah untuk memberikan penyuluhan, pelatihan pembuatan sumur resapan. Metode: Tahapan sosialisasi ini meliputi: 1) Penyuluhan tentang fungsi dan manfaat sumur resapan, 2) Penyuluhan tentang konstruksi sumur resapan, 3) Demonstrasi cara membuat sumur resapan dalam upaya penanggulangan banjir, 4). Monitoring dan Evaluasi dalam kegiatan ini adalah melakukan pengawasan dan evaluasi pembangunan sumur respon di masyarakat. Berdasarkan hasil kegiatan yang telah dilakukan, kegiatan tersebut berjalan dengan lancar. Hasil: Dari hasil evaluasi menggunakan metode penyebaran kuesioner setelah dilakukan penyuluhan di dapatkan bahwa sebanyak $75 \%$ peserta sosialisasi mempunyai pengetahuan kategori baik tentang sumur resapan, sedangkan sebanyak $25 \%$ peserta mempunyai pengetahuan kategori cukup. Kesimpulan: Dengan demikian, kegiatan pengabdian masyarakat ini memberikan manfaat positif bagi mitra tentang pengetahuan pentingnya sumur resapan dan sebagai rencana tindak lanjut dapat disosialisasikan kepada masyarakat tentang pengurangan risiko banjir sehingga mampu memberikan kesadaran kepada masyarakat pentingnya membangun sumur resapan untuk upaya penanggulangan banjir.
\end{abstract}

\section{A B S T R A C T}

Background: This infiltration well is a practical and environmentally friendly way to accelerate the absorption of flood rainwater. The purpose of this community service is to provide counseling, training in making infiltration wells. Method: The stages of this socialization include: 1) Educating about the functions and benefits of infiltration wells, 2) Training about infiltration well construction, 3) Demonstration of how to make infiltration wells in flood prevention efforts, 4). Monitoring and evaluation in this activity is to supervise and evaluate the construction of respective wells in the community. Based on the results of the activities that have been carried out, these activities are running smoothly. Result: From the results of the evaluation of the distribution of the questionnaire after counseling, it was found that as many as $75 \%$ of the socialization participants had good category knowledge about respon wells, while $25 \%$ of participants had sufficient category knowledge. Conclusions: Thus, this community service activity is expected to provide positive benefits for partners about knowledge of the importance of infiltration wells and as a follow-up plan it can be disseminated to the community about reducing flood risk so as to provide awareness to the community of the importance of building infiltration wells for flood prevention efforts. 


\section{PENDAHULUAN}

Peristiwa banjir yang terjadi di berbagai daerah Indonesia sebagian besar disebabkan oleh ulah manusia, seperti kurangnya kesadaran dalam menjaga dan melestarikan lingkungan serta pemanfaatan lahan yang salah (Surur, 2020). Dalam memanfaatkan sumber daya alam berupa tanah dan air harus dilaksanakan dengan menerapkan kelestarian, keserasian dan pemanfaatan yang optimal, karena merupakan salah satu modal dasar pembangunan nasional yang memberikan banyak manfaat bagi masyarakat seperti ekonomi, ekologi, dan keseimbangan sosial. Tanah dan lahan yang tidak sesuai dalam pemanfaatannya akan menyebabkan lahan kritis yang tidak dapat menyerap air pada saat musim hujan. Salah satu penyebab terjadinya banjir merupakan kurangnya kesadaran masyarakat dalam menjaga dan melestarikan lingkungan (Yuliani \& Palembang, 2020). Hal ini perlu adanya upaya dalam melestarikan lingkungan terutama pada lahan kritis agar dapat menyerap air, mengembalikan kesuburan tanah, dan membantu kelestarian daya dukung lingkungan dengan memanfaatkan fungsi sumur resapan (W et al., 2016). Peristiwa banjir ini menjadi pokok permasalahan pada kota-kota dengan pertumbuhan penduduk yang cukup padat (Satriawansyah \& Setiawan, 2016). Meski sudah diadakannya saluran air namun pada saat hujan belum dapat menampung air secara maksimal sehingga air meluap dan menyebabkan banjir. Seperti pada Daerah Singonegaraan Kec. Pesantren Kota Kediri yang belum aman dari masalah banjir. Letak geografis daerah Singonegaran mempunyai kontur tanah yang rendah daripada jalan raya. Hal ini menjadi latar belakang daerah Singonegaran dijadikan mitra pengabdian masyarakat.

Curah hujan yang tinggi di Kota Kediri dan kurangnya kesadaran masyarakat dalam pemanfaatan penggunaan lahan menjadi faktor turunnya fungsi lingkungan (Kuncoro et al., 2018). Oleh sebab itu, untuk mengembalikan fungsi lingkungan serta mengatasi masalah banjir pada Kota Kediri perlu di adakan sumur resapan (Susanto, 2019). Sumur resapan adalah salah satu rekayasa teknik konservasi air berupa bangunan yang dibuat sedemikian rupa sehingga menyerupai bentuk sumur gali dengan kedalaman tertentu yang berfungsi sebagai tempat menampung air hujan yang jatuh di atas atap rumah atau daerah kedap air dan meresapkannya ke dalam tanah.

Penerapan sumur resapan ini di tujukan pada daerah-daerah yang memiliki kondisi risiko tanah kritis dan kurang efektifnya sistem drainase (Susanto, 2019). Dengan demikian, perlu diadakan sosialisasi sumur resapan ini pada lingkungan yang padat penduduk dengan tingkat resapan air yang rendah dan rawan terjadi banjir pada saat penghujan. Salah satu daerah yang membutuhkan adanya sumur resapan yaitu lingkungan RW 6 Desa Singonegaraan Kec. Pesantren Kota Kediri. Kegiatan pengabdian masyarakat ini menjadi alternatif dalam upaya pencegahan banjir dan melestarikan lingkungan, karena kurangnya sosialisasi masyarakat dalam mengatasi upaya banjir. Dengan adanya kegiatan sosialisasi ini harapan kedepannya dapat meningkatkan kesadaran dan kepedulian masyarakat Desa Singonegaraan Kec. Pesantren Kota Kediri dalam menjaga lingkungan serta mengatasi banjir. Masyarakat memahami pentingnya sumur resapan 
dan mampu membuat sumur resapan untuk mencegah banjir. Serta dapat menjadi pelopor dalam melestarikan lingkungan dengan memanfaatkan sumur resapan dalam mengatasi banjir. Tujuan dari pengabdian masyarakat ini adalah melakukan sosialisasi sumur resapan dalam upaya penanggulangan banjir.

\section{MASALAH}

Masalah yang dihadapi mitra saat ini adalah adanya banjir saat musim hujan dengan ketinggian kurang lebih $15 \mathrm{~cm}$. Ketinggian banjir tersebut menggangu aktifitas sehari-hari warga di sekitar tempat pengabdian. Banjir biasanya menggenangi sebanyak 80\% jalan yang ada di wilayah Singonegaran Kec. Pesantren Kota Kediri. Berdasarkan wawancara dengan perwakilan warga wilayah Singonegaran sebanyak $80 \%$ belum memahami tentang penanggulangan banjir. Hasil dari pengamatan menunjukkan bahwa kondisi jalan dan drainase yang masih terbilang kurang terawat. Banyak sampah dan bebatuan menyumbat saluran drainase, permukaan jalan yang tidak rata, bahkan hampir semua jalan menggunakan aspal yang dapat memperkecil ruang penyerapan air. Sebagai solusi permasalahan mitra ini bisa dilakukan dengan melakukan sosialisasi penanggulangan banjir dengan pembangunan sumur resapan.

\section{METODE PELAKSANAAN}

Kegiatan sosialisasi penanggulangan banjir ini meliputi beberapa tahapan sebagai berikut : 1). Melakukan survei daerah mitra yang selanjutnya dijadikan peserta program kemitraan, 2). Melakukan kordinasi dengan pihak perangkat desa dan ketua RT setempat, 3). Memberikan penyuluhan dan sosialisasi meliputi upaya penanggulangan banjir dengan sumur resapan. Materi sosialisasi ini meliputi: 1). Penyuluhan tentang fungsi dan manfaat sumur resapan, 2). Penyuluhan tentang konstruksi sumur resapan, 3). Demonstrasi cara membuat sumur resapan dalam upaya penanggulangan banjir ,4). Monitoring dan Evaluasi dalam kegiatan ini adalah melakukan pengawasan dan evaluasi pembangunan sumur resapan di masyarakat. Tahap selanjutnya setelah melakukan tahap diatas adalah dengan melakukan evaluasi tentang pengetahuan masyarakat dengan menyebarkan kuesioner kepada peserta penyuluhan.

\section{HASIL DAN PEMBAHASAN}

Pengabdian masyarakat diawali dengan survei pengamatan ke lokasi. Lokasi yang dipilih adalah wilayah Desa Singonegaraan Kec. Pesantren Kota Kediri. Hasil dari pengamatan, Desa Singonegaraan menunjukkan bahwa kondisi jalan dan drainase yang masih terbilang kurang terawat. Banyak sampah dan bebatuan menyumbat saluran drainase, permukaan jalan yang tidak rata, bahkan hampir semua jalan menggunakan aspal yang dapat memperkecil ruang penyerapan air. Dikala curah hujan tinggi sering terjadi banjir. 


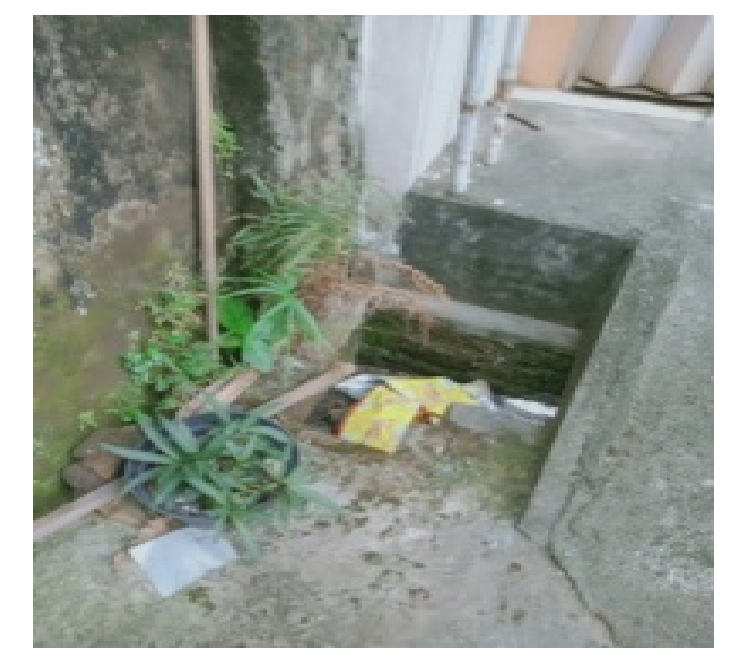

Gambar 1. Kondisi Jalan dan Drainase Mitra

Informasi dari masyarakat sekitar menyatakan bahwa desa ini sering terjadi banjir dikala curah tinggi, dan dikala curah hujan tidak tinggi air menggenang dijalanan desa ini. Hal ini disebabkan karena saluran drainase tersumbat dan mungkin didalam drainase terdapat endapan tanah yang tinggi, sehingga air meluap atau air sulit masuk. Solusi dari tim pengabdian masyarakat kepada warga adalah dengan membersihkan saluran drainase dari sampah, bebatuan, dan endapan tanah atau bisa membuat sumur resapan agar tidak terjadi banjir atau genangan air dijalan (Astriani \& Angarini, 2020). Pada kegiatan pengamatan lokasi di Desa Singonegaraan ,dalam hal ini desa tersebut telah memenuhi kriteria dan sesuai dengan topik kegiatan yang akan diangkat.

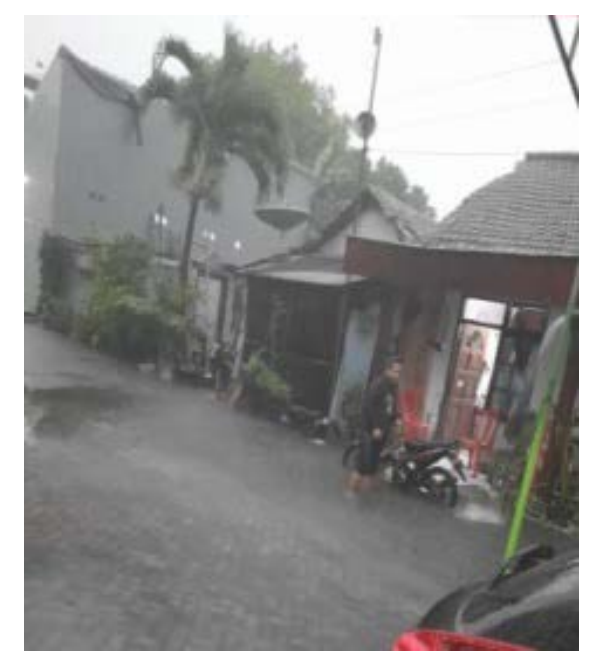

Gambar 2. Kondisi genangan air pada saat musim hujan di daerah mitra

Pelaksanaan kegiatan pengabdian masyarakat ini dilaksanakan dengan tujuan memberikan pemahaman bagi warga Desa Singonegaraan RW 06 tentang pentingnya pengendalian banjir. Tahapan kedua yang dilakukan adalah melakukan kordinasi dengan pihak perangkat desa dan ketua RT setempat. Kegiatan ini dilakukan untuk mendapat dukungan dan ijin dari pihak yang berwenang. 


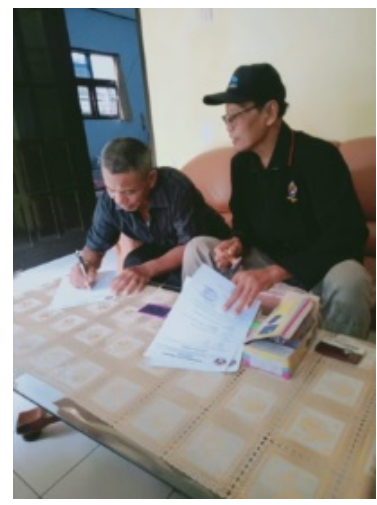

Gambar 3. Kordinasi perijinan dengan pihak desa

Tim pengabdiaan masyarakat memberikan penyuluhan yang berjudul "Penanggulangan Banjir di Wilayah Desa Singonegaraan Kec. Pesantren Rw 06 Kota Kediri", dilakukan pada bulan Desember 2020 yang diikuti oleh 10 peserta yang sosialisasai dilakukan dari rumah ke rumah karena pada saat pandemi dengan tetap memperhatikan protokol kesehatan Materi sosialisasi ini meliputi: 1). Penyuluhan tentang fungsi dan manfaat sumur resapan, 2). Penyuluhan tentang konstruksi sumur resapan, 3). Demonstrasi cara membuat sumur resapan dalam upaya penanggulangan banjir . Kegiatan pelatihan untuk membuat sumur resapan dapat dilakukan dengan 8 langkah yaitu : 1) mempersiapkan alat dan bahan seperti pipa PVC, talang, semen, ijuk, pasir, buis beton, batu pecah, bata merah, dan linggis ; 2) Penggalian lubang tanah dengan kedalaman $3 \mathrm{~m}$ dan diameter $100 \mathrm{~cm}$ (tidak melebihi muka air tanah) ; 3) Pemasangan buis beton pada lapisan dinding sumur resapan yang bisa dikombinasikan dengan batu bata untuk menahan tekanan dari tanah agar tidak terjadi longsor ; 4) Pembuatan bak control (Bahunta \& Waspodo, 2019) ; 5) Pembuatan dan pemasangan talang air ; 6) Pemasangan pipa pada sumur resapan yang berfungsi untuk membuang limpahan air saat sumur resapan kelebihan air ; 7) Tambahkan ijuk dan batu pecah kedalam lubang sumur resapan ; 8) Pakaikan alas penutup sumur yang berupa plat beton dan diurug dengan tanah secukupnya supaya struktur sumur jadi terlindungi (Basuki Setiyo Budi, 2015).

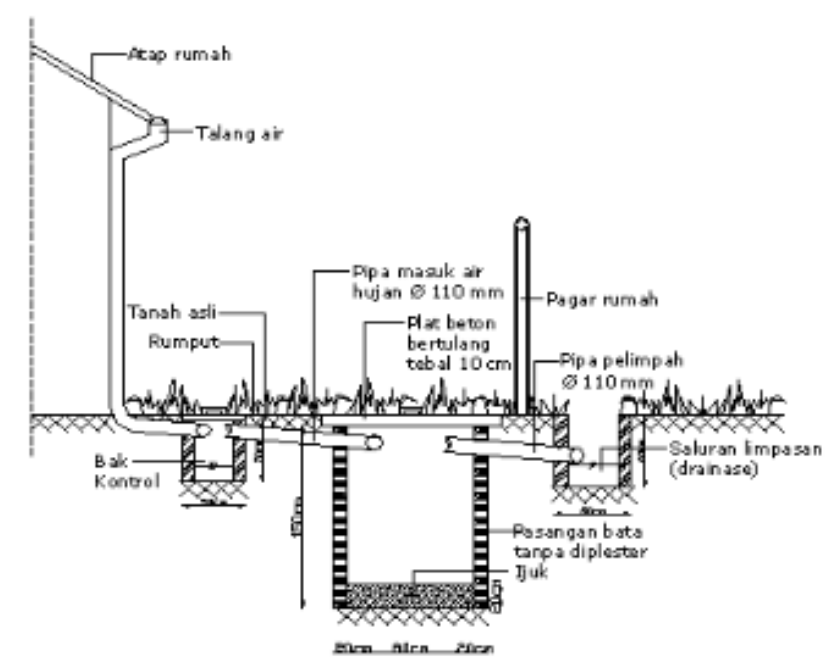

Gambar 4. Konstruksi Sumur Resapan tampak melintang (Iriani \& Gunawan, 2013) 


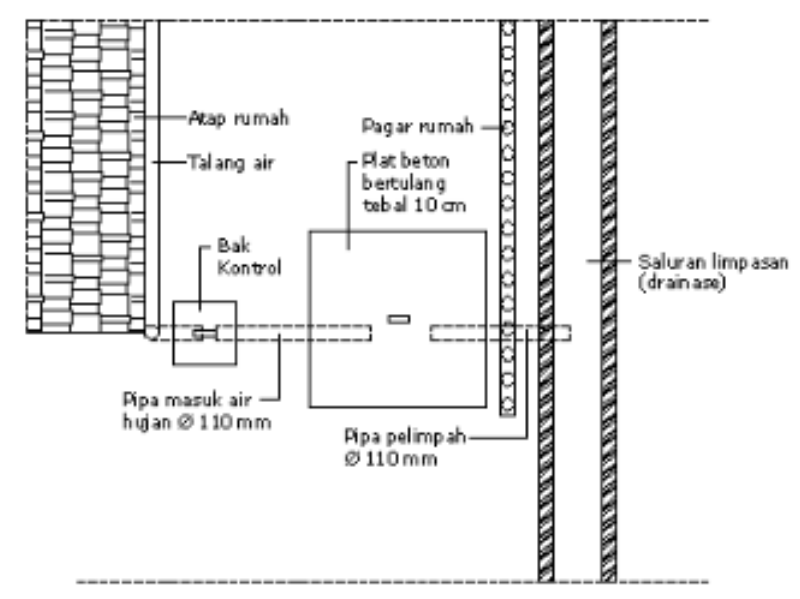

Gambar 5. Konstruksi Sumur Resapan tampak atas (Iriani \& Gunawan, 2013)

Setelah dilakukan kegiatan sosialisasi didapatkan hasil bahwa peserta sangat antusias untuk bertanya dalam penyuluhan dan sangat mendukung kegiatan ini mengingat wilayah tersebut sering terjadi banjir. Setelah mengikuti penyuluhan ini diharapkan warga memahami penting membuat sumur resapan. Kegiatan penyuluhan tentang pengendalian risiko banjir dengan solusi membuat sumur resapan berjalan dengan lancar dan para peserta begitu antusias dan sangat mendukung kegiatan seperti ini. Setelah memperhatikan langkah - langkah dalam membuat sumur resapan dari awal sampai akhir. Mereka berpendapat bahwa pembuatan sumur resapan itu mudah namun sangat bermanfaat bagi kelangsungan ketersediannya air tanah yang berkualitas dan dapat menanggulangi terjadinya banjir maupun genangan air yang bisa menimbulkan nyamuk DBD. Dan jika terjadi kelebihan air pada sumur resapan, maka air hujan akan dialirkan masuk ke dalam saluran drainase(Phoa, 2014).

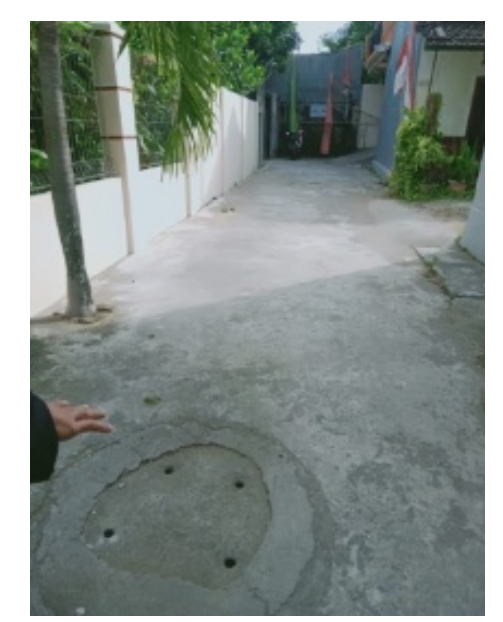

Gambar 6. Hasil Pembangunan Sumur Resapan

Kegiatan penyuluhan tentang pengendalian risiko banjir dengan solusi membuat sumur resapan berjalan dengan lancar dan para peserta begitu antusias dan sangat mendukung kegiatan seperti ini(Susanto et al., 2020). Kegiatan ini diikuti oleh 10 peserta yang sosialisasai dilakukan dari rumah ke rumah karena pada saat pandemi dengan tetap memperhatikan protokol kesehatan Dari hasil evaluasi penyebaran kuesioner setelah dilakukan penyuluhan di dapatkan bahwa sebanyak $75 \%$ peserta sosialisasi mempunyai pengetahuan kategori baik, sedangkan sebanyak $25 \%$ peserta mempunyai pengetahuan kategori cukup. Rencana tindak lanjut kegiatan pengabdian 
masyarakat dilakukan untuk mengamati, mengecek, dan memantau kelancaran kegiatan yang telah dilakukan. Upaya mengurangi risiko bencana seperti banjir dapat dilakukan dengan cara menjaga dan melestarikan lingkungan sekitar (Lindarto et al., 2018). Selain cara mengurangi risiko banjir adalah mengubah perilaku buruk terhadap lingkungan seperti membuang sampah sembarangan, meningkatkan kesadaran kepedulian tentang pentingnya merawat lingkungan (Karuniastuti, 2014). Langkah yang perlu mengurangi resiko banjir adalah dengan membuat sumur resapan didepan rumah aau membuat resapan biopori (Basuki Setiyo Budi, 2015).

\section{KESIMPULAN}

Kegiatan sosialisasi penanggulangan banjir di desa Singonegaran , Kediri meliputi beberapa tahapan sebagai berikut meliputi 4 tahap. Kegiatan yang dilakukan meliputi penyuluhan tentang fungsi dan konstruksi sumur resapan. Tahap selanjutnya juga melaksanakan demonstrasi cara membuat sumur resapan. Tahap yang terakhir adalah monitoring dan evaluasi dengan memberikan kuesioner kepada peserta penyuluhan. Berdasarkan hasil kegiatan yang telah dilakukan, kegiatan tersebut berjalan dengan lancar yang diikuti oleh 10 peserta yang dilakukan penyuluhan dengan menerapkan protokol kesehatan Covid-19. Dari hasil evaluasi penyebaran kuesioner setelah dilakukan penyuluhan di dapatkan bahwa sebanyak $75 \%$ peserta sosialisasi mempunyai pengetahuan kategori baik tentang sumur respan, sedangkan sebanyak 25\% peserta mempunyai pengetahuan kategori cukup. Rekomendasi rencana tindak lanjut untuk kegiatan selanjutnya adalah mensosialisasikan kepada masyarakat tentang pengurangan risiko banjir sehingga mampu memberikan kesadaran kepada masyarakat pentingnya membangun sumur resapan untuk upaya penanggulangan banjir.

\section{UCAPAN TERIMA KASIH}

Ucapan terima kasih disampaikan kepada pihak-pihak yang membantu pelaksanaan kegiatan ini yaitu warga desa Singonegaran, Kota Kediri dan LPPM Universitas Kadiri dan mahasiswa yang terlibat dalam kegiatan ini.

\section{DAFTAR PUSTAKA}

Astriani, M., \& Angarini, E. (2020). Penyuluhan Sampah dan Teknik Pengolahannya di Kelurahan 14 Ulu Palembang. Jurnal SOLMA, 09(02), 361-366.

Bahunta, L., \& Waspodo, R. (2019). Rancangan Sumur Resapan Air Hujan sebagai Upaya Pengurangan Limpasan di Kampung Babakan, Cibinong, Kabupaten Bogor. Jurnal Teknik Sipil Dan Lingkungan., 04(01)

Basuki Setiyo Budi, M. (2015). Pemanfaatan lrb dalam mengatasi genangan air, Banjir dan kekeringan di kecamatan Banyumanik. Jurnal Polines, 4(2), 29-40. 
Iriani, K., \& Gunawan, A. (2013). Perencanaan Sumur Resapan Air Hujan Untuk Konservasi Air Tanah DI daerah Pemukiman (Studi Kasus Di Perumahan RT. II, III, Dan IV Perumnas LIngkar Timur Bengkulu). Jurnal Linersia, 5(1), 9-21.

Karuniastuti, N. (2014). Teknologi Biopori Untuk Mengurangi Banjir dan Tumpukan Sampak Organik. Jurnal Polines, 1(2), 60-68.

Kuncoro, M. A., Winarto, S., \& Setianto, Y. C. (2018). Studi Penanggulangan Banjir di Kali Batan Kabupaten Kediri. Jurnal Jurmateks, 1(1).

Lindarto, D., Harisdani, D. D., \& Abdillah, W. (2018). Partisipasi Masyarakat Dalam Penggunaan Teknik Biopori Untuk Mengendalikan Banjir Kota. NALARS Jurnal Arsitektur, 17(2), 97-104.

Phoa, V. B. (2014). Perencanaan Embung Resapan Untuk Pengendalian Banjir di Kabupaten Tulungagung. Skripsi. Depertemen Teknik Sipil. Institut Teknologi Nasional Malang.

Satriawansyah, T., \& Setiawan, D. (2016). Perencanaan Sumur Resapan Dan Lubang Resapan Biopori Sebagai Alternative Penanggulangan Banjir Di MAN 1 Sumbawa Besar. Jurnal Saintek, 1(2).

Surur, F. (2020). Pemetaan Lingkungan Madrasah Tanggap Bencana Secara Partisipatif di MTsN 2 Bone. Jurnal SOLMA. Jurnal SOLMA, 09(1), 102-112.

Susanto, S. et. a. (2019). Perbandingan Fungsi Keanggotaan Tipe Segitiga dan Tipe G-Bell Terhadap Analisis Risiko. Jurnal U Karst, 3(2), 57-67.

Susanto, S., Hendy, Sumargono, Winarno, B., \& Candra, A. I. (2020). Measurement Of Occupational And Health Risk Levels Of Kadiri University LP3M Building. Jurnal U Karst, 4(2).

W, B., Sir, W., \& Penna, C. . (2016). Pemanfaatan Sumur Resapan Untuk Meminimalisir Genangan Di Sekitar Jalan Cak Doko. Jurnal Teknik Sipil, 04(01).

Yuliani, E. H., \& Palembang, U. M. (2020). Penerapan Perilaku Hidup Bersih Sehat Penduduk terhadap Cara Pengelolaan Sampah Rumah Tangga. Jurnal SOLMA, 09(1), 68-78. 